\title{
A Educação de Jovens e Adultos da classe trabalhadora sob o fogo cruzado da Pedagogia do Medo
}

\author{
The Adult and Youth Education of the working class under the crossfire \\ of Pedagogy of Fear
}

\section{La Educación de Jóvenes y Adultos de la clase trabajadora bajo el fuego cruzado de la Pedagogía del Miedo}

SONIA MARIA RUMMERT $®$

Universidade Federal Fluminense, Niterói, RJ, Brasil.

$\diamond$

\begin{abstract}
RESUMO
O trabalho objetiva suscitar o debate acerca da problemática da Educação de Jovens e Adultos trabalhadores no Brasil, referindo, inicialmente, a dificuldades que marcam sua história recente e que constituem expressões de antiga e estrutural supressão do direito da classe trabalhadora à educação plena e de qualidade socialmente referenciada. A seguir, trata-se da circunstância histórica delineada a partir do último processo eleitoral que marcou o ingresso do País em um tempo em que vige a Pedagogia do Medo, convergente, em algumas de suas características gerais, com outros processos verificados no mundo ocidental, ao longo do século XX, configurados como regimes de força. Concluímos indicando algumas possibilidades de construção coletiva de resistência e luta na atual conjuntura brasileira que, segundo o nosso entendimento, podem contribuir para a travessia para a qual somos convocados, visando a enfrentar o desafio e o fardo desse tempo histórico.
\end{abstract}

Palavras-chave: Educação de Jovens e Adultos trabalhadores. Política educacional. Educação da classe trabalhadora. Pedagogia do Medo.

\begin{abstract}
This article aims at raising the debate about the problems of adult and youth education workers in Brazil. Initially it refers to the difficulties that mark its recent history and constitute expressions of structural suppression of the working class right to full and quality education. Moreover, it deals with the historical circumstances outlined from the last election that marked the entry of the country into a time in which the Pedagogy of Fear converges, in some of its general characteristics, with other processes found in the western world throughout the 20th century, featured as power regimes. The conclusion indicates some possibilities of collective construction of resistance and struggle in the current Brasilian historical moment which may contribute, according to our understanding, to confront the challenge and the burden of this historical time.
\end{abstract}

Keywords: Education of Young and Adult Workers. Educational policy. Education of the working class. Pedagogy of Fear.

\section{RESUMEN}

El trabajo objetiva suscitar el debate acerca de la problemática de la Educación de Jóvenes y Adultos trabajadores en Brasil. Se refiere, inicialmente, a dificultades que marcan su historia reciente y que constituyen expresiones de la estructural supresión del derecho de la clase trabajadora a la educación plena y de calidad socialmente referenciada. A continuación, se trata de la circunstancia histórica delineada a partir del último proceso electoral que marcó el ingreso del país en un tiempo en que rige la Pedagogía del Miedo, convergente, en algunas de sus características generales, con otros procesos verificados en el mundo occidental, a lo largo del siglo XX, configurados como regímenes de fuerza. Concluimos indicando algunas posibilidades de construcción colectiva de resistencia y lucha en la actual circunstancia brasileña que, según nuestro entendimiento, pueden contribuir a la travesía hacia la que estamos convocados, buscando enfrentar el desafío y el fardo de ese tiempo histórico.

Palabras clave: Educación de Jóvenes y Adultos de la Clase Obrera. Política educativa. Educación de la clase obrera. Pedagogía del Miedo. 


\section{INTRODUÇÃo}

Este trabalho, apresentado sob a forma de ensaio, objetiva, a partir da análise da atual problemática que caracteriza a Educação de Jovens e Adultos Trabalhadores no Brasil, alvo de intenso processo de desmonte e de desqualificação, propiciar o debate acerca não só dessa modalidade de ensino, mas da Educação Básica quando destinada à classe trabalhadora. Para tanto, tomamos como objeto de reflexão o cenário que se avizinha para os próximos anos, a partir dos resultados do recente processo eleitoral de 2018 que levou à presidência da República um candidato de extrema-direita, além de promover a composição de um Congresso Nacional também de caráter majoritariamente conservador, como não havia se constituído nas últimas três décadas no País.

Inicialmente, destacamos não ser recente o fato de que as políticas e as práticas voltadas para a Educação de Jovens e Adultos constituem, no Brasil, alvo de diversas ameaças por parte do Estado, em suas três esferas de governo: federal, estadual e municipal. Em decorrência disso, destacamos, no primeiro tópico, de forma sucinta, exemplos desse quadro, que requer resistência e luta, e cuja gravidade vem sendo apontada por profissionais envolvidos de diferentes formas no cotidiano escolar da Educação de Jovens e Adultos, bem como em produções de origem acadêmica.

$\mathrm{O}$ próprio cenário em que se materializa essa modalidade de ensino, nos últimos anos, já justifica a convocação para resistir e lutar por condições dignas de vida para todos, o que inclui com destaque o direito à educação, em respeito à nossa própria humanidade e à nossa existência como seres sociais e individuais.

Entretanto, nos últimos dias do mês de outubro, abateu-se sobre tal cenário forte ameaça à educação, à classe trabalhadora, ao País. Ameaça essa alçada ao poder pela via da democracia liberal ${ }^{1}$ e, portanto, restrita, a partir de seu instrumento legal: o voto.

O que se apresenta para o futuro próximo é um quadro de diferentes formas de ataque a essa frágil democracia,

\footnotetext{
1 A democracia, no Estado Moderno, baseia-se na sociedade de classes, caracterizada, genericamente, pela exploração de uma classe por outra, o que é antagônico ao princípio da igualdade, como assinalou Lênin, ao afirmar que se há exploração "não poderá existir igualdade" (LÊNIN, 1997, p. 15). Essa concepção também nos é apresentada por Mészáros, em duas obras fundamentais: A teoria da alienação em Marx (1981) e Para além do capital (2006), nas quais apresenta o conceito de democracia substantiva. Acerca dessa nomenclatura, esclarece o autor em artigo de 2015: “uso a expressão 'substantivamente democrático' (e, é claro, 'democracia substantiva', cujas características definidoras fundamentais a tornam indissociável da 'igualdade substantiva') em contraste inclusive com a concepção de democracia, que já foi genuinamente liberal e que, sob nenhuma condição, poderia ser substantiva, mesmo que tenha conseguido ser mais ou menos substancial em um sentido político limitado. Nesse sentido limitado, a política pode ser mais ou menos 'substancialmente democrática' sob um regime liberal, mas jamais poderá ser substantivamente democrática" (MÉSZÁROS, 2015, p. 32).
}

legitimado por sua própria estrutura formal. O extenso dano já causado à sociedade brasileira, antes mesmo da posse do presidente eleito, só tende a se agravar, o que exige resistência coletiva, ampla e urgente.

Pretende-se, a partir dessas considerações, apresentar alguns elementos que contribuam para compreender a dimensão das dificuldades a serem enfrentadas, em particular no âmbito da Educação de Jovens e Adultos Trabalhadores, ressaltando que essas não são independentes das demais, mas se agravam diante da atual conjuntura, favorável à denominada pedagogia do medo $^{2}$, que se instala no País. Compreender algumas dessas dificuldades, bem como a forma como os regimes de força, ao longo do século XX abordaram a educação e dela se valeram, torna-se fundamental no presente momento.

Para concluir, nas "Considerações finais", indicamos algumas possibilidades de construção coletiva de resistência e de luta, para as quais nós, educadores, comprometidos com a democracia substantiva (MÉSZÁROS, 2015) e com a emancipação humana (MARX, 1989), devemos nos preparar nesse conturbado tempo histórico que se avizinha, de modo que a crítica não se esgote no universo da produção acadêmica.

\section{O CONTEXTO BRASILEIRO DE RESISTÊNCIA E LUTA EM QUE SE INSCREVE, NA ATUALIDADE, A EDUCAÇÃo DE JovenS E Adultos TrabalHAdores}

Como sublinhado por diversos especialistas da área, já há alguns anos, e recentemente com mais intensidade, a Educação de Jovens e Adultos vem sofrendo um intenso processo de desmonte e de desqualificação. A tendência, que se aprofunda cada vez mais, pode ser evidenciada em toda a sua materialidade no fato de que a dotação orçamentária - expressão concreta da vontade política para a modalidade, no âmbito público, cada vez mais se afasta de qualquer princípio de isonomia com a educação regular.

No que se refere particularmente ao Fundo de Manutenção e Desenvolvimento da Educação Básica e de Valorização dos Profissionais da Educação - Fundeb, por exemplo, deve-se assinalar o fato de que à modalidade Educação de Jovens e Adultos é atribuído o menor fator de ponderação no cálculo do valor-aluno. Em detido estudo sobre o financiamento da EJA, via Fundeb, até o ano de 2010, Carvalho (2014) chama atenção para o fato de que,

\footnotetext{
${ }^{2}$ Em apropriação livre de expressão utilizada por Maestri (2004), especialista em história da escravidão no Brasil, que aborda esse modo de produção como tendo sido, sobretudo, um processo que, pela disseminação do medo, visou a disciplinar condutas, consolidar hierarquias sociais e forjar uma concepção de mundo favorável à dominação.
} 
apesar da inclusão da modalidade de ensino no Fundo ter constituído um avanço, os entes federados mantiveram baixos os índices percentuais a ela destinados.

Afirma ainda o autor que:

A inclusão do financiamento da EJA no Fundeb foi ponto positivo, afinal o fundo anterior excluíra esta modalidade. Sem embargo, tais avanços têm que ser vistos com muita cautela, principalmente devido aos seguintes fatores: o crescimento no investimento aconteceu, mas em termos comparativos com gestões (FHC, por exemplo) que investiram muito pouco na EJA, inclusive com a tentativa de desresponsabilizar o Estado e sua transferência para a sociedade civil, o aporte aumentou, mas ainda era exíguo para atender com qualidade social o público jovem e adulto excluído ou que não completou seus estudos, apesar de o ensino fundamental ser obrigatório desde 1988; os programas/ campanhas de curta duração continuaram como tônica de muitas das ações adotadas (CARVALHO, 2014, p. 651).

Essa é a mesma posição de Di Pierro, ao chamar atenção para o fato de que:

Uma matrícula em EJA vale $80 \%$ do que vale a matrícula de um aluno na primeira fase do ensino fundamental urbano, que tem o maior fator de ponderação. Isso incentiva muito pouco o dirigente de ensino a investir nessa modalidade educacional (DI PIERRO, [2016]).

Essa ausência de isonomia constitui, segundo nosso entendimento, um fator determinante para o retrocesso vivenciado pela Educação de Jovens e Adultos no País, mas não podemos absolutilizar, uma vez que essa defasagem dá, também, materialidade ao fato de que o direito de todos à educação básica ainda não constitui um valor civilizatório incorporado à totalidade social. Em decorrência, a pressão social pelo cumprimento do direito educacional dos jovens e adultos trabalhadores é bastante incipiente, o que se agrava pelo fato de que mesmo no âmbito da educação, a grande maioria dos profissionais que se mobiliza por sua manutenção em bases minimamente satisfatórias é integrada, majoritariamente, pelos efetivamente envolvidos com a EJA. Isso concorre de forma significativa para a opção de investimento insuficiente - e cada vez mais reduzido - por parte das diferentes esferas administrativas, uma vez que a ausência de pressão social que sustente a modalidade como política pública a fragiliza, sobremaneira.

Esse quadro se concretiza, no âmbito das redes públicas, por meio de diferentes ações, entre as quais podemos citar como mais relevantes:

a) o encerramento dos turnos e de turmas dedicados à EJA, com expressiva redução da oferta de vagas, a reestruturação para menos de seu currículo específico e/ou a redução do período presencial em até $50 \%$ da carga horária que passa a ser oferecida a distância em diversas redes públicas;

b) o fato de que as diferentes esferas do Estado abdicam de suas atribuições constitucionais, agindo como verdadeiros indutores da desescolarização dos jovens e adultos trabalhadores com a substituição do ensino regular por programas aligeirados e precários que associam suposta elevação de escolaridade com formação profissional;

c) a ênfase na promoção de rearranjos escolares denominados como de aceleração, aligeirados e precários, que se apresentam como alternativa ao considerado longo percurso escolar e anunciados como mais adequados para quem não pode perder tempo mas que, na verdade, atendem aos interesses da ótica gerencial de correção de fluxo idade-série e de redução de custos, oferecendo aos egressos tão somente o que Kuenzer denominou de "certificação vazia" (2005);

d) as diferentes formas de precarização e privatização que se concretizam pela ação de diferentes agências não escolares da sociedade civil que disputam o fundo público, pela implementação de programas e campanhas, pelo incentivo a que as agências empresariais assumam a tarefa precípua do Estado, pelos cursos privados, presenciais ou a distância, que proliferam sem o controle;

e) o não cumprimento, pelo Estado, de seu papel indutor, o que concorre significativamente para a redução da procura das redes públicas por parte dos milhões de demandantes em potencial, tema que requer análise ainda não empreendida satisfatoriamente e fundamental para a compreensão plena da questão;

f) a continuidade da pouca ou nenhuma possibilidade de formação específica inicial e continuada para os docentes da EJA que atuam nas redes públicas, bem como a permanente ausência de disciplinas relativas a essa modalidade de ensino na grande maioria dos cursos de licenciatura, inclusive os de pedagogia, em todo o País.

Esses são graves problemas com os quais temos que nos defrontar, com cada vez mais intensidade, já há vários anos. Problemas candentes que reafirmam o fato de que, no Brasil, a lógica dominante, lamentavelmente com grande capilaridade no tecido social, considera desnecessário ou pouco estratégico assegurar a milhões de jovens e adultos o direito objetivo e subjetivo à educação plena, à formação integral. 
Essa lógica, ancorada na visão dos seres humanos tão somente como insumo econômico, a serem qualificados apenas segundo as demandas dos processos produtivos, também concorre para justificar, de forma cruel, o fato de a Educação de Jovens e Adultos Trabalhadores não ser uma real prioridade nas políticas sociais, a não ser quando objetiva formações precárias para trabalhos precários.

Essa "marca social" (GRAMSCI, 2000) da Educação de Jovens e Adultos Trabalhadores se coaduna com a lógica maior que rege a educação nos países de capitalismo dependente, como é o caso do Brasil (FERNANDES, 1973). Para Florestan Fernandes, a compreensão do conceito de capitalismo dependente no Brasil requer que sejam consideradas, dialeticamente, tanto as leis gerais que regem o padrão de desenvolvimento capitalista quanto as especificidades da formação social brasileira na divisão internacional do trabalho. É no âmbito desse processo sócio-histórico, o qual não pode ser analisado aqui, que se inscreve a educação da classe trabalhadora brasileira, constituindo clara expressão das demandas do modo de produção capitalista no cenário da hegemonia internacional. Brevemente, podemos considerar que o estudo da Organização Internacional do Trabalho (2017), intitulado "Tendências Globais de Emprego para a Juventude" corrobora o aqui afirmado ao ressaltar que:

\begin{abstract}
Houve um declínio na demanda por habilidades de nível médio, enquanto a demanda por trabalhadores altamente qualificados e menos qualificados está crescendo, contribuindo para uma maior polarização no mercado de trabalho. A demanda por jovens altamente qualificados cresceu fortemente em países de renda alta, enquanto nos países em desenvolvimento e emergentes houve um aumento no trabalho de baixa habilidade. [...] Essa tendência de polarização do trabalho pode ser acentuada pelas novas tecnologias e potencialmente exacerbar as desigualdades existentes (ORGANIZAÇÃO INTERNACIONAL DO TRABALHO, 2017).
\end{abstract}

Consideramos que o trecho aqui destacado ilustra as mazelas do capitalismo dependente, trazendo à tona $o$ fato de ser o quadro hegemônico internacional o grande regulador da educação da classe trabalhadora, em particular quando essa é gerida estritamente pela classe dominante, como é o caso brasileiro.

Aos aspectos acima referidos de forma sucinta se somam, agora, outras ameaças que atingem toda a educação pública, além de todas as demais políticas sociais. Compreender as diferentes possibilidades de ataque à educação em períodos históricos precedentes é um passo essencial para que, sem cair no risco do anacronismo, possamos refletir acerca das tarefas que temos a partir de agora.

\section{A EDUCAÇÃO DA CLASSE TRABALHADORA SOB O FOGO CRUZADO DA PEDAGOGIA DO MEDO}

Para abordar esse novo e complexo desafio serão apresentadas a seguir algumas considerações acerca da educação, a partir do fundamental apoio da história que, como o próprio pensamento conservador reconhece, é uma ciência revolucionária, do que deriva o sistemático ataque de que é alvo.

Como sabemos, a educação transcende em muito a sua abordagem enquanto modalidade de ensino vinculada à forma-escolar. Educação popular, educação em saúde, pedagogia social, educação sociocomunitária, por exemplo, são algumas das muitas possibilidades que caracterizam complexos e ricos campos de conhecimento que se entrelaçam e, mesmo, se completam.

Na verdade, já na década de 1930, Paschoal Lemme (1953), importante intelectual da educação brasileira, pouco lembrado, já mencionava, em monografia sobre a educação de adultos, mais de trinta denominações em diferentes países para as ações que, a partir de diversas perspectivas, voltavam-se para as pessoas que, por razões diferenciadas, demandavam ações educativas de caráter intencional. Essas diferentes vertentes da educação, trazem, nas sociedades contemporâneas, traços sóciohistóricos muitas vezes convergentes, dentro de suas significativas especificidades e diferenças.

Tanto essas diferentes vertentes quanto a própria educação escolar registram em sua história no mundo ocidental ao longo do século XX a marca da repressão pelos regimes de força como, por exemplo, a pedagogia social, que se consolidou como formulação teórica e prática sistemática na Alemanha do século XIX, que foi completamente desarticulada quando da ascensão de Hitler ao poder. Também no âmbito da educação formal europeia, o nazismo, o fascismo, o franquismo e o salazarismo, investiram duramente sobre a educação básica e sobre as universidades, seja pela legislação imposta que colocava os sistemas escolares a serviço do ideário totalitário, seja pela prisão/ exílio/tortura e/ou morte de muitos intelectuais e estudantes.

Do mesmo modo, a educação popular na América Latina foi, nas décadas de 1960, 1970 e 1980, reprimida com violência pelas ditaduras civil-militares, tendo-se como exemplo paradigmático a violenta repressão aos movimentos de educação popular que vicejaram no Brasil, predominantemente, a partir do início da década de 1960, e foram violentamente reprimidos após o Golpe de 1964. Também, a ditadura civil-militar brasileira e as impostas à Argentina, ao Peru, ao Uruguai, ao Chile, à Nicarágua e à Bolívia atuaram fortemente sobre à educação, visando 
a transformar os sistemas escolares em seus aparelhos de hegemonia (GRAMSCI, 1999).

Nesses regimes de força verificou-se um conjunto de ações que tinha por objetivo a "depuração" ideológica da sociedade como um todo, e do magistério em particular, além do abandono dos princípios laicos da educação formal. Em decorrência, importantes intelectuais ligados à educação para a libertação, para a conscientização e a emancipação humana, entre os quais o maior destaque nacional e internacional foi Paulo Freire, foram perseguidos, presos e/ou exilados.

Essas ações, que incidiram violentamente sobre o complexo e multifacetado campo da educação, possuíam expressivas convergências, entre as quais podemos destacar:

a) o forte deslocamento dos princípios da formação humana ampla, democrática e livre para a conformação, para a sujeição à ordem autoritária e para a dominação;

b) o deslocamento da ideia de opositores - com quem é necessário dialogar - para a de inimigos, que precisam ser eliminados de forma simbólica ou mesmo real. Entre esses inimigos estavam os professores, tidos como perigosos por serem potenciais propagadores para todos, desde a mais tenra idade, da ideologia inimiga da nação, em detrimento da suposta verdade de que os dominantes eram os portadores;

c) a disseminação da pedagogia do medo entre os descontentes e a divisão da sociedade entre aqueles que concordavam ativa ou passivamente e os outros, os inimigos, a serem rechaçados.

Não podemos, sob pena de cometer o erro do anacronismo, transpor linearmente para os dias atuais as marcas dos momentos históricos referidos acima. Por outro lado, não devemos ignorar o fato de que estamos diante de novas formas de atuação sistemática de um projeto conservador e autoritário, que guarda similitudes com traços do fascismo, embora essa caracterização não seja consensual por parte dos analistas sociais.

De todo modo, há indicadores concretos de que a nossa incipiente e vulnerável democracia liberal está em risco. Desses indicadores, podem ser destacados alguns que ilustram a argumentação e que se encontram diretamente ligados à complexa problemática da educação, seja na "forma-escolar", seja nas diferentes ações empreendidas em outras agências da sociedade civil comprometidas com a emancipação humana, tais como os apresentados a seguir:

a) o lema hoje apregoado "O Brasil acima de todos" visa a sedimentar no imaginário social a imagem simbólica do País como uma unidade "sadia", pregando uma espécie de higienismo cultural, moral e racial. Nessa suposta sociedade sadia há um papel muito específico e restrito a ser desempenhado pela escola, a partir da lógica do movimento "Escola sem Partido", que vem constituindo objeto de estudos como, por exemplo, os de Penna (2017a; 2017b);

b) o recrudescimento da difusão de necessidade de engajamento urgente de todos na tarefa de livrar o País do perigo interno, genericamente abrigado por uma noção difusa de comunismo, que ameaça a base da sociedade brasileira, a qual deve ser reconstruída sobre princípios e valores a serem sistematicamente transmitidos pela escola - mas não só - e centrados em determinada concepção de "família", "propriedade", "religião" e "ordem";

c) o ataque à educação e aos professores, que devem ser permanentemente vigiados, inclusive por seus alunos agora, alçados à condição de guardiães dos valores coadunados com a ideologia dominante;

d) a importante base popular em igrejas pentecostais fundamentalistas (neopentecostais), que contrasta com as tradições cristãs brasileiras, mesmo que conservadoras, tanto católicas quanto protestantes tradicionais, bem como com as religiões de matriz africana e outras. A relação direta que se estabelece com a educação escolar é o fato de que não é de hoje que essas igrejas pentecostais fundamentalistas valem-se da estratégia de ocupação das escolas públicas em várias redes de ensino, como vem ocorrendo, há bem mais de dez anos, de diferentes formas na rede estadual e nas redes municipais do Estado do Rio de Janeiro e da Região Nordeste, por exemplo;

e) a defesa da chamada "teologia da prosperidade" e a sua apologia do consumo, que incorpora e propaga as teses neoliberais mais radicais, como a da meritocracia apresentada como valor, em oposição ao que denominam de "vitimismo" dos beneficiários de diferentes políticas sociais específicas, apresentados como os que, na realidade, sangram os recursos de quem é próspero e sustenta a nação. Defende-se, assim, outra cisão na sociedade: entre vencedores e perdedores, introjetada no ideário educacional pela apologia do empresariamento individual.

$\mathrm{Na}$ verdade, não devemos considerar novas essas características da sociabilidade brasileira. O ódio e o desprezo aos chamados pobres, às mulheres, aos indígenas e aos negros, por exemplo, estão profundamente enraizados no que Caio Prado Junior (2000) denominou como herança colonial e constituem marcas que se integram nas diferentes vertentes de dominação de classes 
no País. Entretanto, como assinala Leher, essa herança colonial ganha hoje novo fôlego no País a partir de

setores fundamentalistas vinculados a igrejas e centros de pensamento ultraconservador, que abrem uma agenda moral, sobre comportamentos, controle de visão de mundo, que faz convergências com agendas que já estavam em curso, no bojo da política institucional, como a agenda empresarial. [...] São propostas que promulgam que a escola não pode tornar pensáveis os problemas que a humanidade enfrenta no tempo presente, que ela não pode ser uma escola de ciência, porque a ciência sempre envolve a problematização do conhecimento estabelecido (LEHER, [2016]).

Ao referir-se particularmente ao "Escola sem Partido", em reflexão que podemos generalizar para a totalidade do pensamento alçado ao poder, Leher ressalta a intenção de cristalizar a concepção de que "a escola não pode ser uma instituição capaz de problematizar os valores, as perspectivas de vida, o horizonte de mundo. Não é só uma lógica econômica, é um horizonte para a formação humana no Brasil” (LEHER, [2016]).

Podemos dizer que essas marcas são orgânicas à nossa formação histórico-social. Não são novas, portanto, as suas matrizes que hoje nos afrontam. Não foi o presidente eleito e seus seguidores que inventaram a barbárie anunciada, já anteriormente posta em prática, incentivada desde o período eleitoral e agudizada a partir de 28 de outubro de 2018.

Entretanto foi, sobretudo, o presidente eleito, como representante da extrema-direita, que se tornando o seu porta-voz, elaborou a síntese discursiva acolhida por significativa parcela dos eleitores e que conferiu legitimidade ao ódio, manifestando-o publicamente e o instituindo como uma direção política de governo, autorizada pelo voto popular da democracia liberal e restrita.

No processo multifacetado desse período ultraconservador, destacamos três aspectos que se delineiam como fortes ameaças à formação humana comprometida com a democracia substantiva e à emancipação humana e que espraiam o medo entre os que não abdicam de seus valores democráticos:

a) a criminalização da esquerda e dos movimentos sociais comprometidos com as transformações sociais, que engloba também, como ameaça a ser combatida, toda a atividade docente que não se enquadre no escopo do ideário ultraconservador, em todos os níveis de ensino;

b) a militarização da vida civil, pela possível liberação do porte de armas, acirrando a violência social que fatalmente irá repercutir nas escolas; pelo incentivo ao denuncismo discente e pela militarização das escolas públicas de educação básica já em curso e que certamente irá se ampliar;

c) os ataques à liberdade de expressão, de ensino e de criação cultural a partir de uma moral conservadora, racista, misógina e homofóbica.

Nesse cenário, foi difundido um discurso específico de desqualificação e de ódio direcionado aos professores, apresentados como "doutrinadores esquerdistas" e, mesmo, responsáveis pela "imoralidade" que se instalou nas escolas e para além delas, como já referido aqui.

No processo que se agiganta e que requer organização, resistência e luta, vemos avizinhar-se o ataque violento à categoria docente quando esses professores estão fortemente desgastados pelas lutas cotidianas de sobrevivência decorrentes da precarização do trabalho e da própria vida, muitas vezes enfrentando, além dos baixos salários, frequentemente recebidos com meses de atraso, a violência que atravessa os muros escolares, a desconsideração e a desvalorização impostas pelo próprio Estado, marcas que se materializam sobremaneira na Educação de Jovens e Adultos Trabalhadores, como apontado anteriormente.

É nesse contexto social, político e econômico que necessitamos nos organizar coletivamente de modo a enfrentar o "desafio e o fardo do [nosso] tempo histórico", como refere Mészáros (2007), em suas reflexões sobre as formas de consciência, bem como acerca da educação e de suas marcas no modo de produção capitalista.

\section{REFLEXões, A Título de CONCLUSÃo, SOBRE A CONSTRUÇÃO DA RESISTÊNCIA HOJE}

Voltamos aqui, ao âmbito específico da Educação de Jovens e Adultos Trabalhadores, predominantemente marcada, no Brasil e na América Latina, pela história das lutas e das resistências. Voltamos a tratar, especificamente, dos jovens e adultos subalternizados e alvos históricos da violência, da discriminação, do arbítrio e da indiferença. Do mesmo modo, voltamos a tratar dos professores e educadores que vivenciam, também, em suas lutas cotidianas, diferentes formas materiais e simbólicas de violência, de desqualificação, de arbítrio.

Nós, professores e educadores, estamos profissionalmente envolvidos com a Educação de Jovens e Adultos, portanto, ética e politicamente, comprometidos com maiores alvos de ataque: imensas frações da classe trabalhadora constituídas, em seu caráter multifacetado, por diferentes etnias, por distintas orientações sexuais e identidades de gênero, pelos integrantes dos movimentos sociais, como o Movimento dos Trabalhadores Sem Terra (MST), o Movimento dos Trabalhadores Sem Teto, os 
movimentos quilombolas, os movimentos dos atingidos por barragens etc, entre muitos outros que compõem o imenso contingente de seres destituídos dos direitos básicos inerentes à vida digna. Nós, também integrantes da classe trabalhadora na condição de professores, educadores e/ou de militantes dos movimentos sociais e partidos políticos progressistas, estamos gravemente ameaçados, no exercício de nosso ofício, e já somos e poderemos ser, ainda mais, vítimas de ataques, como em outros momentos da história.

Esse caráter multifacetado não elide a centralidade da origem de classe e da posição de subalternidade em que estamos colocados. Em decorrência, faz-se imperioso construir o maior número possível de elos societários que possam vir a nos fortalecer enquanto sujeitos coletivos. Faz-se necessário, portanto, ultrapassar o círculo da educação e buscar interlocução e apoio no conjunto da sociedade.

É fundamental, portanto, atuar na direção que nos é apontada por Luciano Mendes que, em texto recente sobre o atual momento político, afirmou não ser

possível pensarmos na resistência apenas no campo da educação. Ou é uma resistência capilarizada, organizada e articulada com os mais diversos setores democráticos do país, ou seremos engolidos pela onda fascista que assola o país e que, agora, ganhará ares de oficialidade e de política de Estado (MENDES FARIA FILHO, [2018]).

A história do tempo presente nos impõe o desafio de construir formas de articulação reais e amplas entre as instituições escolares - escolas de educação básica, profissional e universidades - e os movimentos sociais que abrigam a gênese e a concretização da educação popular. Esse é um fecundo e necessário ponto de partida para construir a capilaridade fundamental da resistência organizada e articulada, que não se opõe às resistências plurais e multifacetadas. Ao contrário, as supõe e as fortalece (MENDES FARIA FILHO, [2018]). Não se trata de ignorar as especificidades da luta, mas de orientar o nosso modo de estar no País pelo compromisso com a solidariedade ético-política. Nenhum problema pode ser apenas nosso.

$\mathrm{O}$ ataque às diferentes etnias, os ataques homofóbicos, os ataques misóginos, a negação aos direitos básicos, a criminalização dos movimentos sociais e dos vários e necessários movimentos políticos de esquerda, a criminalização dos que atuam no âmbito educacional, em sua pluralidade institucional, são problemas de todos nós. O que se aproxima de modo avassalador atingirá a muitos, e todos somos vulneráveis ao arbítrio, sobretudo se nos mantivermos isolados.
A nosso favor, a especificidade do trabalho docente voltado para o contato sistemático com jovens e adultos da classe trabalhadora que acorrem à escola e que, cotidianamente, a enriquecem e a desafiam com a sua experiência de classe. Tal experiência de classe confunde-se hoje, no Brasil, com a situação de expropriação que se manifesta na vida diária, por exemplo, pela precarização das políticas sociais que, cada vez mais reduzidas e privatizadas, cerceiam o acesso da classe trabalhadora ao fundo público, submetendo-a as mais perversas condições de privação e de exploração.

$O$ desafio de educar requer que busquemos, permanentemente, a formação plena. E, para "que tal processo de formação seja pleno, é fundamental que o professor construa a consciência de sua natureza inconclusa" (RUMMERT, 2016, p. 27). Essa perspectiva vai ao encontro de Vieira Pinto que, por compreender o professor como um trabalhador social (VIEIRA PINTO, 1982), destaca ter a educação a marca do "imperativo da desalienação" (VERA PINTO, 1982, p. 54). Nesse sentido, "é imprescindível que o educador se converta à sua realidade, seja antes de tudo do seu próprio povo, ou melhor, das camadas populares de sua nação. Aceitar 'ser do' país é o primeiro passo para compreender o 'ser' do país" (VERA PINTO, 1982, p. 54).

A compreensão do ser do país, isto é, da complexidade de sua essência (KOSIK, 1978), nos indica um primeiro elemento da resistência: o estudo sistemático. Trata-se de criar grupos de estudo, de adesão ampla (docentes, discentes, familiares, amigos) para, periodicamente, estudar visando a compreender em profundidade os condicionantes históricos, culturais, sociais, econômicos e políticos do presente. O estudo, nesse momento, não é algo que nos roube tempo de luta e resistência. Ao contrário, é fundamental para construirmos coletivamente, sempre coletivamente, os caminhos possíveis e necessários, fundamentados na realidade concreta e não em devaneios voluntaristas.

Ainda em 2015, Conceição Paludo nos alertava sobre a necessidade de estudar ou, em suas palavras, sobre a necessidade de "adentrar na teoria e reorientar as práticas" (PALUDO, 2015, p. 16). Nessas considerações finais dialogamos com as suas indicações, para apontar a importância de estudar para poder conhecer minimamente os reais elementos explicativos do processo que culminou com a eleição do representante das forças de extrema-direita. Essa compreensão, que precisa ser largamente partilhada, torna-se essencial para a reorientação de nosso trabalho pedagógico e de nossa ação permanente como trabalhadores sociais. Para tanto, se faz necessário estudar para:

a) conhecer efetivamente as contribuições do legado daqueles que, em diferentes períodos históricos, nos precederam e lutaram sistemática e coletivamente 
contra o arbítrio e a opressão organizados como política de Estado;

b) compreender as questões relativas às necessidades humanas e ao mundo do trabalho, enquanto produção da existência, em suas dimensões ontológica e histórica, no Brasil de hoje e às relativas vicissitudes daí advindas;

c) analisar os processos de formação do Brasil contemporâneo a partir da historicidade do capitalismo dependente que nos caracteriza;

d) apreender os aspectos centrais de "complexa questão da cultura enquanto manifestação identitária e, também, de forma mais ampla, como concepção de mundo, permeada pela lógica dominante" (PALUDO, 2015, p. 13), bem como pelas suas múltiplas formas de ressignificação e resistência.

Como já referimos, a Educação de Jovens e Adultos Trabalhadores não se restringe à escolaridade formal, mas também engloba um universo extremamente amplo de experiências informais e não formais de formação humana que se concretizam fora do espaço-tempo escolar. É nesse âmbito, por exemplo, que emergiram as históricas iniciativas de educação popular que marcaram a primeira metade da década de 1960. Uma de suas características comuns -e fundamental - foi o princípio fecundo de intersecção entre a educação e a cultura popular, como por exemplo, na "Campanha De pé no chão também se aprende a ler" e no trabalho de alfabetização de adultos realizado por Paulo Freire.

A riqueza desses trabalhos, fartamente documentada, evidencia o fato de que, na educação formal, há muito que aprender com os movimentos sociais e com os seus educadores. Do mesmo modo, os movimentos sociais devem se aproximar da escola, conhecer as suas particularidades, os seus dilemas e possibilidades e assumir como a sua a tarefa de lutar em sua defesa como o faz, por exemplo, o MST, que dela não abdica. Esse é um aspecto muito positivo dentro do momento atual, porque nos impõe a ruptura de barreiras e nos aproxima do outro de uma forma efetiva.

Se nos reportarmos a essas iniciativas, em particular aos Círculos de Cultura de que se valia Paulo Freire (1979) para dar início ao seu trabalho de alfabetização, desde a experiência de Angicos, encontraremos fonte inspiradora para empreender trabalhos similares nas escolas, com profissionais da educação e com os discentes jovens e adultos; também nos bairros em que estão as escolas em que atuamos e, ainda, junto a diferentes grupos, sobretudo de vulnerabilizados à luz do atual cenário.

Trata-se de empreender ações de educação como conscientização, a partir da reflexão rigorosa sobre a complexa realidade em que vivemos, para o que podemos nos preparar a partir dos estudos concomitantes de temas como os enunciados anteriormente.
Além disso, impõe-se, para todos os movimentos sociais e sindicais bem como para cada um de nós, um desafio, dentre muito outros: a defesa intransigente e ativa da educação pública, que constitui, no Brasil, um legado histórico de várias gerações, ainda não conquistado plenamente e que, embora inconcluso, está em risco.

Faz-se necessário, assim, trabalhar no sentido de socializar amplamente a compreensão de que a educação e a escola não constituem um patrimônio ou um "problema" que diz respeito apenas aos profissionais da educação. $\mathrm{O}$ patrimônio educacional de uma sociedade pertence a toda a sociedade e lutar por ele e defendê-lo é também tarefa imperativa de toda essa sociedade.

Esse patrimônio, bem como todo aquele que vem sendo construído pelas forças políticas progressistas ao longo da nossa história republicana, marcada por largos períodos ditatoriais, está em jogo e profundamente ameaçado. No caso específico da educação da classe trabalhadora e, em particular, de seus jovens e adultos, verifica-se um acúmulo de processos de degradação que, agora, pode culminar com o desmonte do modelo de escola pública que ainda conseguimos até hoje preservar, em que pesem os seus graves problemas que constituem expressão de questões estruturais. Nesse cenário, é fundamental tomarmos como tarefa urgente assumir coletivamente a indicação de Vieira Pinto quando alerta para a necessidade de que os profissionais da educação se comprometam capilarmente com o imperativo da desalienação.

\section{REFERÊNCIAS}

CARVALHO, Marcelo Pagliosa O financiamento da EJA no Brasil: repercussões iniciais do Fundeb. Revista Brasileira de Política e Administração da Educação, [S. l.], v. 30, n. 3, p. 635-655, set./dez. 2014. https://doi.org/10.11606/t.48.2012. tde-23042012-154314

DI PIERRO, Maria Clara. Revista Época. Entrevista. Disponível em: https://epoca.globo.com/ideias/noticia/ 2016/06/maria-clara-di-pierro-perdemos-32-milhoes-dematriculas-na-educacao-de-jovens-e-adultos.html. Acesso em: 10 out. 2018. https://doi.org/10.5965/1984724616312015245

FERNANDES, Florestan. Capitalismo dependente e classes sociais na América Latina. Rio de Janeiro: Zahar, 1973.

FREIRE, Paulo. Educação como prática da liberdade. Rio de Janeiro: Ppaz e Terra, 1979.

GRAMSCI, Antonio. Caderno 12. Apontamentos e notas dispersas para um grupo de ensaios sobre história dos intelectuais. In: GRAMSCI, Antonio. Cadernos do Cárcere, v. 2: Os intelectuais, o princípio educativo. Jornalismo. Rio de Janeiro: Civilização Brasileira, 2000. https://doi.org/ 10.11606/d.48.2010.tde-12112010-143733 
GRAMSCI, Antonio. Caderno 11. Apontamentos e notas dispersas para um grupo de ensaios sobre história dos intelectuais. In: GRAMSCI, Antonio. Cadernos do Cárcere, v. 1: Introdução ao estudo da filosofia. Rio de Janeiro: Civilização Brasileira, 1999. https://doi.org/10.14393/revedfil. issn.0102-6801.v28n55a2014-p59a98

KOSIK, Karel. Dialética do concreto. Rio de Janeiro: Paz e Terra, 1978.

KUENZER, Acácia. Exclusão includente e inclusão excludente: a nova forma de dualidade estrutural que objetiva as novas relações entre educação e trabalho. In: LOMBARDI, J.; SAVIANI, D.; SANFELICE, J. (org.). Capitalismo, trabalho e educação. São Paulo: Autores Associados; HISTEDBR, 2005. p. 77-96.

LEHER, Roberto. Não é só uma lógica econômica, é um horizonte para a formação humana no Brasil. Portal EPSJV/ Fiocruz, Rio de Janeiro, 2016. Entrevista. EPSJV/Fiocruz/05/ 07/2016 Disponível em: http://www.epsjv.fiocruz.br/noticias/ entrevista/nao-e-so-uma-logica-economica-e-um-horizontepara-a-formacao-humana-no-brasil. Acesso: ago. 2018.

LEMME, Paschoal. Estudos de educação. Rio de Janeiro: Livraria Tupã, 1953.

MAESTRI, Mário. A pedagogia do medo: disciplina, aprendizado e trabalho na escravidão brasileira. In: STEPHANOU, Maria; BASTOS, Maria Helena Câmara. (org.). Histórias e memórias da educação no Brasil. Séc. XVI-XVIII. Petrópolis: Vozes, 2004. v. 1, p. 192-209.

MARX, Karl. A questão judaica. In: MARX, Karl. Manuscritos econômico filosóficos. Lisboa: Edições 70, 1989. p. 35-76.

MENDES FARIA FILHO, Luciano. Organizar a Resistência na Educação: uma agenda democrata. In: Pensar a Educação Pensar o Brasil, 2018. Disponível em: http:// pensaraeducacao.com.br/blogpensaraeducacao/organizara-resistencia-na-educacao-uma-agenda-democrata/. 29 de outubro de 2018. Acesso: 6 nov. 2018.

MÉSZÁROS, István. A teoria da alienação em Marx. Rio de Janeiro: Zahar Editores, 1981.

MÉSZÁROS, István. Igualdade substantiva e democracia substantiva. São Paulo: Boitempo, 2015. p. 32. (Margem Esquerda. Ensaios marxistas, n. 25).

MÉSZÁROS, István. O desafio e o fardo do tempo histórico: o socialismo no século XXI. São Paulo: Boitempo, 2007.

MÉSZÁROS, István. Para além do capital. São Paulo: Boitempo, 2006.

OIT - Brasília. Tendências Globais de Emprego para a Juventude 2017. Fraca recuperação nos mercados de trabalho juvenil exige uma resposta abrangente. Disponível em: https:// www.ilo.org/brasilia/noticias/WCMS_597076/lang--pt/index. htm. Acesso em: 5 out. 2018.
PALUDO, Conceição. Educação popular como resistência e emancipação humana. Cadernos CEDES, Campinas v. 35, n. 96, p. 235, maio-ago. 2015.

PENNA, F. A. "Escola Sem Partido" como ameaça à Educação Democrática: fabricando o ódio aos professores e destruindo o potencial educacional da escola. In: MACHADO, A. R. de A.; TOLEDO, M. R. de A. (org.). Golpes na História e na Escola. São Paulo: Cortez: ANPUH-SP, 2017b. v. 1. p. 247-260.

PENNA, F. A. O Escola sem Partido como chave de leitura do fenômeno educacional. In: FRIGOTTO, Gaudêncio (org.). Escola "sem partido": esfinge que ameaça a educação e a sociedade brasileira. Rio de Janeiro: UERJ, LPP, 2017a. v. 1. p. 35-48.

PINTO, Álvaro Vieira. Sete lições sobre educação de adultos. São Paulo: Autores Associados; Cortez, 1982.

PRADO JÚNIOR, Caio. Formação do Brasil contemporâneo. São Paulo: Brasiliense: Publifolha, 2000.

RUMMERT, Sonia Maria. A atualidade das contribuições de Paschoal Lemme e de Álvaro Vieira Pinto à educação de adultos. Revista Brasileira de Educação de Jovens e Adultos, Salvador, v. 4, n. 7, 2016.

Recebido em: 30/3/2019.

Aprovado em: 15/10/2019.

Publicado em: 21/12/2019.

Endereço para correspondência:

Sonia Maria Rummert

Universidade Federal Fluminense - Campus do Gragoatá

Rua Alexandre Moura, 8, Bloco D, sala 526 - São Domingos

24210-200,Niterói, RJ, Brasil

Autora:

SONIA MARIa RumMERT

Doutora em Ciências Humanas - Educação, PUC-RJ. Professora do Programa de Pós-graduação em Educação da Universidade Federal Fluminense (UFF). Niterói, RJ, Brasil.

Orcid: https://orcid.org/0000-0003-1187-8786

E-mail: rummert@uol.com.br 